\title{
Assessment of Preferred Ecological Restoration Approach through Stakeholders' Attitude in Ghana. (A Case Study in Adubriem Village in Ashanti Bekwai)
}

\author{
Emmanuel Owusu $^{1 *} \quad$ Li Fanglin ${ }^{2} \quad$ Nelly Ataawomba Afuubi ${ }^{3}$ \\ 1.School of Finance and Economics, Jiangsu University, 301 Xuefu Road, Jingkou District, Zhenjiang, Jiangsu, \\ China \\ 2.School of Statistics, Jiangsu University, 301 Xuefu Road, Jingkou District, Zhenjiang, Jiangsu, China \\ 3.School of Finance and Economics, Jiangsu University, 301 Xuefu Road, Jingkou District, Zhenjiang, Jiangsu, \\ China
}

This research is financed by the National Natural Science Foundation of China and the grant number 71503105 Abstract

Restoring disturbed abandoned mine lands form an integral part of a mining process. Recognized mining entities are tracked by stakeholders on their restoration activities unlike illegal miners who destroy lands and create burdens for the government. The extent to which ecosystems have been destroyed in Ghana has pressured government to bear the cost of restoration. This research looks at preferred approaches government can use to restore abandoned mine sites. The research used a stakeholder analysis and questionnaires to analyze opinions and preferences towards ecological restoration. The approaches included government-based restoration, community based and payment for ecosystem services (PES). From the research community members preferred community based ecological restoration to the others. The research showed that members either agreed or strongly agreed community mining was an effective way of solving the issue of illegal mining. The research also showed community members believed community mining was a collective effort to protect the environment

Keywords: Ecological restoration, illegal mining, government-based restoration, community mining, Payment for ecosystem services (PES)

DOI: $10.7176 / \mathrm{JEP} / 11-24-01$

Publication date: December $31^{\text {st }} 2020$

\section{INTRODUCTION}

Ecological restoration has formed an important part in our quest to conserve the environment. Brownfield activities such as oil industry and mining industry take ecological restoration very serious in their operations as a result of government and social pressure.

The safe, environmental, and social risks arising from badly conducted mine closure can result in significant liabilities for mining companies. For communities, closure can cause severe distress because of the threat of economic and social collapse. In the case of illegal mining entities who are not accountable for the environmental damages in the course of their operations, the disturbed lands from their operation could led to enormous negative impact on the economy, environment and social integrity of the community and country in general. Abandoned mines may result in large clean-up costs and closure liabilities for governments (World Bank, 2002). Illegal mining popularly referred to as "Galamsey" which was derived from the phrase "Gather them and sell" is a social menace causing havoc to many natural ecosystems in Ghana. According to Ghana Minerals Commission, there are about 20,000 to 50,000 illegal miners as of 2013 and their operations are increasing at an exponential rate. These operations have lasted over decades until it was recently banned by Government in 2017 . There are no doubts these operations provide some sources of employment in Ghana but needs to be regulated by government to prevent it from destroying the society and environment as reported by The Africa Report in 2013. The Government of Ghana has placed a ban on illegal mining, and this has led to many individuals becoming unemployed. The ban intends to stop all and regulate illegal mining operation whiles the government plans to make provisions for the restoration of these disturbed sites. As the government seeks to implements this plan the research analyzes the preferred approach toward ecological restoration which will be a win -win for all stakeholders involved.

\section{LITERATURE REVIEW}

\subsection{Ecological restoration}

The Society for Ecological Restoration broadly describes restoration as "the process of assisting the recovery of an ecosystem that has been degraded, damaged, or destroyed." Ecological restoration has traditionally been defined as an act of returning a system to an original state, and is distinguished from rehabilitation, which is more broadly defined as any act to improve the degraded state of the ecosystem. Intact or "original" ecosystems will have both high structural and functional attributes compared to degraded systems. While 'remediation,' 'reclamation,' 'enhancement,' and 'mitigation' are also activities performed on degraded ecosystems, the outcome of these 
activities is an alternative state or partial recovery of an original state. For our purposes, we define restoration as any combination of activities intended to result in ecological uplift, improve ecosystem health, and result in a functioning ecosystem that provides a suite of ecosystem services (i.e. the beneficial functions of ecological systems according to World Resources Institute, 2005. These activities may include conservation activities-such as the purchase of conservation easements, land acquisition, or transfer of water rights only when such investments are a part of a larger restoration effort. By defining the restoration economy around the industries that contribute to these efforts, we inductively define restoration as being comprised of the set of economic activities that contribute to restoration, from project planning, engineering and legal services, to intermediate suppliers of inputs, to on-the-ground earthmoving, forestry, and landscaping firms that contribute to the ecological restoration process. During mining there are many different activities that lead to the destruction of the ecosystem. They include clearing large swathes of vegetation, destroying of topsoil and subsoil to get to the raw material. During the process of mining processed water referred to as tailings is stacked in a dam or adjacent farmland which is typical of galamsey. The tailings produced by mining activities need a large area, referred to as the tailings pool, for stacking. With the disposal of the tailings, the original ecosystem of the tailings pool is seriously affected (Chen et al., 2016). In Ghana, most areas blessed with gold deposit have been destroyed by galamsey and the government plans to restore the lands to a productive use like farming or forestry.

\subsection{Justification of Ecological restoration}

Nature is beautiful and we should value, preserve, and restore the beauty of the Earth, as we would for a beautiful or historical building or painting. I, my children, and grandchildren deserve to see everything that nature has to offer, not just the remains of overused and abused ecosystems. Even though dinosaurs are extinct, what would you give to see one alive?

Extinction eliminates the potential for people to tap the genetic reservoirs of life. Nearly all our foods, medicines and fibers come directly from, or are synthetically patterned after natural materials. Providing future generations with the means of life, including the cure for disease, requires the preservation and restoration of ecosystems. If nature breaks down, then human survival is threatened, because we cannot substitute human labor and capital for "free" ecosystem services, such as decomposition, pollination, oxygen recycling, climate regulation, etc. Why would we not intervene in nature if it meant saving ourselves?

The close relationship that develops between people and the land they restore or manage is mutually beneficial. People restore their connection to nature and benignly transform their attitudes towards it, and nature is enhanced as restoration takes place.

Nature has an inherent right to exist. As human society has evolved, rights have been granted to an everwidening circle beyond the individual, extended in recent times to include trees, birds, flowers and all of nature. People have no right to destroy nature. Instead people should do whatever they can to preserve and restore ecosystems to their most natural state.

\subsection{Policies of Ecological restoration}

We define ecological restoration as a practical management strategy that restores ecological processes to maintain ecosystem composition, structure, and function. Successful restoration requires a full understanding of the ecological deficiencies in the ecosystem, a defined course of scientific study through experimental management, and the development of a program for carrying out restoration. Although, our definition of restoration is humancentered, because restorations occur to satisfy people, our intent is to design restoration strategies that ultimately minimize human intervention. Restoration and safeguarding of ecosystems that provide ecosystem services (including degraded land) have been recognized by the international community as means to enhance and maintain biodiversity and ecosystem services, as articulated in Aichi Targets 14and 15 of the Strategic Plan for Biodiversity 2011-2020 agreed by parties to the Convention on Biological Diversity in October 2010 (CBD 2010). As investments in implementing the Strategic Plan accelerate, governments need information on the relative costs and benefits of actions, including ecological restoration, needed to achieve these targets (CBD 2012). The ecologist must acknowledge the dominance of human values in setting goals for restorations. We believe the goal of ecological restoration is the establishment of sustainable, productive ecosystems that benefit humans. Analysis of the costs of restoration and its benefits is very different from short-term cost-benefit analyses for commodity production because the latter often does not factor in long-term loss ecological changes and ecosystem deterioration.

Several political actors, including states and international organizations, such as United Nations Environment Programme, have made declaratory commitment to engage in ecological restoration (Nelleman and Corcoran 2010), although implementation activities typically take place at the regional and especially the local levels. Restoration is seen as offering many benefits, including helping to address global environmental change. Climate change mitigation and adaptation policy, for example, is increasingly relying upon restoration through reforestation for carbon sequestration or restoring wetlands for flood protection. It is also used as a way of 
safeguarding the provision of ecosystem services. Restoration is stressed as a means of achieving the 2020 Biodiversity Targets, the so-called Aichi Targets, including by the European Union (EU; CEC 2011). In addition, it is increasingly seen as important in agricultural policy and in efforts to improve food security, and as a tool for implementing various resource specific policies, for example, the EU Water Framework Directive, whose target is to restore surface waters and ground waters to 'good ecological status' (WFD EC2000/60). Similarly, restoration is widely used a compensation tool in planning decisions to compensate for disruptions to the visual or cultural qualities of landscapes, often bringing in elements of historic practices and a community's sense of place. Restoration projects can target many different ecological systems or landscapes and be conducted both in urban (Platt 2006) and rural areas. Such activities can occur across a variety of scales, from limited and highly localized experiments and hesitant trials, to remediation of industrial, quarrying, or mining sites, to what are best described as 'mega projects', such as the Kissimmee River restoration initiative in central Florida (Whalen et al. 2002), restoration of the prairies in the USA (Ryan 2000), or contemporary water management initiatives in the Netherlands (Drenthen 2009). Projects can also involve the deliberate reintroduction of species that have been lost or made existent at the local level because of changes in land use and other development pressures. Wolf reintroduction policies form a typical example, restoration initiatives that have led to controversies in both Scandinavia and in North America, not least because of local concerns about potential loss of livestock (Gross 2008). River restoration is another focus of project attention, involving the removal of dams, river remeandering and re bouldering (for example, in Sweden, see Lejon et al. 2009), 'daylighting' of culverted rivers, or ecological remediation of urban river banks (for example, in the UK, see Eden and Tunstall 2006).

\subsection{Government efforts in environmental recovery}

Ecosystem restoration efforts have become a booming business in China. Billions of dollars are being spent annually to restore polluted waterways and ecosystems that have been degraded, fragmented, or paved over (Fu et al. 2007; Wang et al. 2007). However, China's environmental sustainability index remains among the lowest in the world (World Bank 2009; Liu 2010). For all the money spent, there is little evidence of the overall effectiveness of China's efforts to enhance environmental sustainability. For example, soil erosion by water has expanded to cover more than an additional 1,000 km2 of land annually over the past 30 years (Wan et al. 2005). More than $60 \%$ of China's large lakes are eutrophic, and the water quality has declined in $>50 \%$ of its rivers (Fu et al. 2007). Recent water assessments suggest that pollution has been increasing in northern China, and a water crisis is, therefore, emerging. Water resource problems alone cost 2.3\% of China's GDP in 2008 (World Bank 2009). It is important to ask why such large costs and efforts are not "turning the tide". Many factors have contributed to the grave challenges facing environmental restoration in China. The burden of a large population, combined with unevenly distributed natural resources and environmental carrying capacity, has severely limited the options for effective environmental management. However, the distribution of the ecological damage is complex, and its driving forces are often unique and vary widely from situation to situation.

\subsection{Community based approach to ecological restoration}

It is unquestionable that humans have been impacting nature's ecosystems for centuries. It is also unquestionable that humans have been benefitting from ecosystem services since the beginning of time - freshwater, clean air, food, etc. However, it was not until recently, within the past 50 years, that humans began to understand the capacity of the Earth, and the limits of its services to society. Community involvement allows for projects to be widely accepted by the public when completed because it requires people to take part in the restoration and feel connected to the space. It is important to note that community involvement can and should occur at any stage of a restoration project, not just the physical restoration work. In the case of brownfield sites, community volunteers will often not be doing the actual restoration but may be very involved in the planning and design process that precedes the clean-up and restoration. Brownfield sites contain contamination, generally in the soil, due to previous industrial or commercial usage, i.e. an oil refinery or chemical factory. Thus, these sites are not suitable for volunteer labor. Through involving the community, differing opinions can be addressed at the outset, rather than when the project is further along. According to SER, federal money to restore and revitalize brownfield sites are only administered to projects that have clear documentation of community involvement. Community members can also offer valuable insight regarding what has been tried in the past, which could impact the trajectory of proposed projects. According to Ghana web article (Article no.1058602) published on September 13, 2020, Government's Community mining Programme (CMP), an initiative in the making since 2018, has the potential to curb the environmentally destructive, and immensely dangerous practice of illegal small-scale mining. The CMP initiative has trained some 4,500 small scale miners in sustainable mining practices at the University of Mines and Technology at Tarkwa and are now being allocated lands by government in the various mining districts nationwide to carry out artisanal mining in a regulated, environmentally friendly way. 


\subsection{Payment for Ecosystem Services}

PES schemes involve payments to the managers of land or other natural resources in exchange for the provision of specified ecosystem services (or actions anticipated to deliver these services) over-and-above what would otherwise be provided in the absence of payment. Payments are made by the beneficiaries of the services in question, for example, individuals, communities, businesses, or governments acting on behalf of various parties. Beneficiaries and land or resource managers enter into PES agreements on a voluntary basis and are in no way obligated to do so. the term PES is used to describe schemes in which the beneficiaries, or users, of ecosystem services provide payment to the stewards, or providers, of ecosystem services. In practice, PES often involves a series of payments to land or other natural resource managers in return for a guaranteed flow of ecosystem services (or, more commonly, for management actions likely to enhance their provision) over-and-above what would otherwise be provided in the absence of payment. Payments are made by the beneficiaries of the services in question, for example, individuals, communities, businesses, or government acting on behalf of various parties. The basic idea behind PES is that those who provide ecosystem services - like any service - should be paid for doing so. PES therefore provides an opportunity to put a price on previously un-priced ecosystem services like climate regulation, water quality regulation and the provision of habitat for wildlife and, in doing so, brings them into the wider economy. The novelty of PES arises from its focus on the 'beneficiary pays principle', as opposed to the 'polluter pays principle'

\section{METHODOLOGY}

\subsection{STUDY AREA}

Bekwai Municipal Assembly (BMA) is one of the 27 districts in the Ashanti Region established under Legislative Instrument (L.I. 1906, 2007). Until recently the Bekwai Municipality was part of the Amansie East District made up of the Bekwai and Bosome-Freho Constituencies. It is in the southern part of Ashanti Region. It shares boundaries with Bosomtwe District in the north, Adansi -North in the south, Bosome-Freho District to the East and Amansie-Central and Amansie -west to the west. The Municipality lies within latitude $6^{\circ} 00^{\prime} \mathrm{N} 6^{\circ} 30^{\prime} \mathrm{N}$ and Longitudes $1^{\circ} 00 \mathrm{~W}$ and $1^{\circ} 35 \mathrm{~W}$. It covers a total land area of about $633 \mathrm{sqkm}$.

Amansie East (Bekwai) is an area endowed with gold deposits in most areas. The area has many galamsey activities going on. The entire District is rich in gold deposits and mining has emerged as the most important economic activity in the communities. Mining companies have acquired almost all the remaining land area in the District for either prospecting or actual mining (Ministry of Food and Agriculture 2010). Apart from the companies with large concessions in the district, there are other interested parties in the mining industry. The activities of small-scale miners, mostly galamsey operators who employ very crude methods to mine for gold are continually increasing in the district. The activities of these various groups are not properly regulated and not well organized as part of a total package development effort even though it goes a long way to alleviate the poverty situation in the district (MVP 2008). AngloGold Ashanti mining company mines on lands owned by the municipality. The company tries its best to employ people from the area but as usual cannot employ everyone. Most abled young boys and girls indulge in galamsey to provide for their families. The rate of deforestation and land degradation is high and collectively has led to government's bold step to ban this illegal activity.

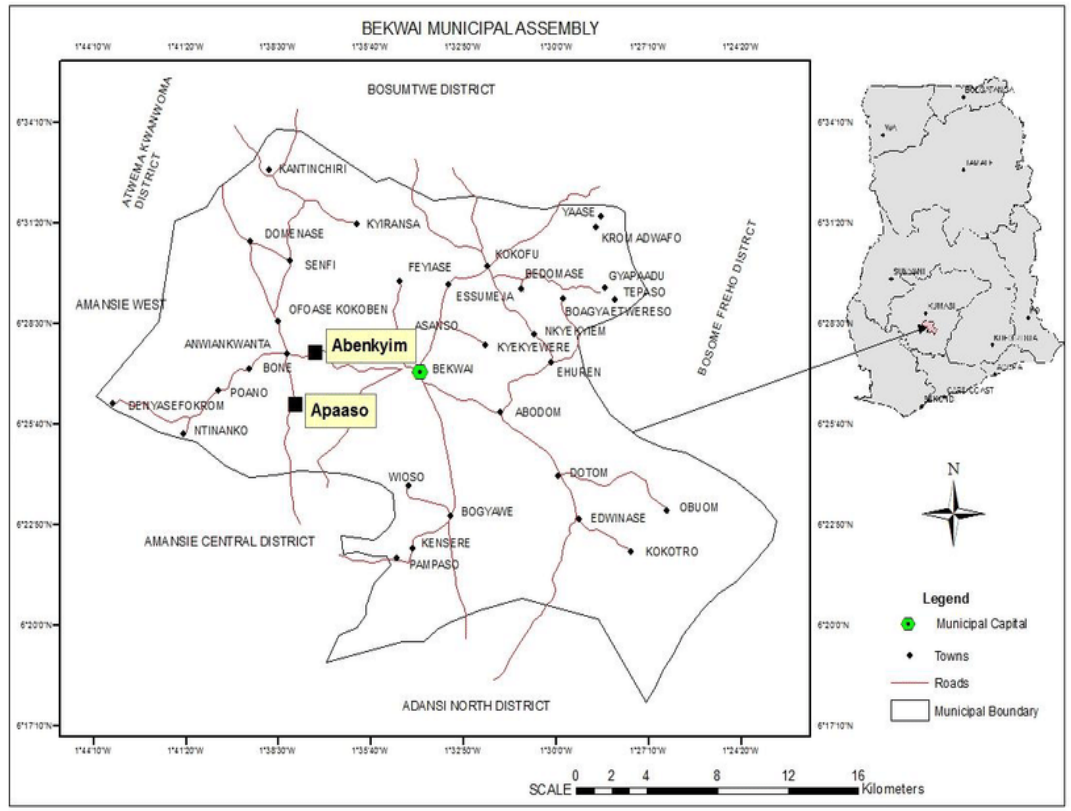

A map of Ghana showing Bekwai Municipal Area 


\subsection{Data Collection}

stakeholder engagement as a technique is used to investigate the behavior and preference of individuals who share similar characteristics (Que et al., 2018). To assess stakeholder attitude towards ecological restoration under varying scenarios using a generated and well-structured questionnaire. Likert scale was used to design questionnaires. The power/interest chart was used to identified and group stakeholders. The varying scenarios include government taking charge of the ecological restoration, community based ecological restoration (community mining), making them restore areas under their operations and finally use of payment for ecological services (PES). A structured questionnaire was used to collect data from all groups of stakeholders. Big mining companies mine responsibly by reclaiming or restoring disturbed lands after their mining activities end. Ghana has been blessed with abundant mineral resources like gold which has encouraged many people to engage in mining activities both legal and illegal. Illegal mining has brought some economic relief to community members but at the same time it has caused a lot of destruction to the country's environment. Illegal mining has provided individuals with immense financial benefits over a period and a direct ban on the activity is going to impact on people. Ecological restoration seeks to restore disturbed lands and tries to seek the consent of stakeholders involved in finding the best approach towards ecological restoration.

Under this research study, ecological restoration approaches were developed to identify the approach stakeholders believe is the best. The approaches identified included

1. Government based ecological restoration.

2. Community based ecological restoration through community mining.

3. Individual based ecological restoration (payment for ecological services).

Stakeholder Identification

Howlett and Nagu define stakeholders as 'all those people and institutions who have an interest in the successful design, implementation and sustainability of the project. This includes those positively and negatively affected by the project. Participation is used in this work to define a process by which stakeholders influence decisions which affect them' and is distinguished from consultation' by the degree to which stakeholders are allowed to influence, share or control the decision-making process (Hughes).

The stakeholders involved in the ecological restoration project included:

Galamsey operators,

Local community members,

Local authority,

Traditional leaders,

Farmers.

A power/interest chart was used to group stakeholders to engage these focus groups. Collecting data was essential by grouping the stakeholders into specific groups based on their power and interest. Questionnaires designed using the Likert scale was used to collected data on stakeholder's attitude towards the different ecological restoration approaches.

\section{RESULTS AND DISCUSSION}

Data collected from stakeholders showed $59 \%$ of community members strongly agreed and $41 \%$ agreed that banning illegal mining will affect community members financially. The data collected showed about $67 \%$ and $31 \%$ strongly agreed and agreed respectively that illegally mining had to be regulated to make it sustainable for the community. The data also showed that members either agreed or strongly agreed community mining was an effective way of solving the issue of illegal mining. The research also showed community members believed community mining was a collective effort to protect the environment because most members are from the area and mining responsibly is to their greater benefits. Unlike corporations operating for short-term profits under state management, the community could hold the natural resource base in trust for future generations (Burda et al. 1997: 89).

According to the research, community members believed government based ecological restoration will not be effective in designing and channeling resources in the restoration project in terms of final land use which might not be economically sustainable. According to a research by Kelly Vodden in 2000, effective and long-lived ecological restoration efforts depend on citizen engagement. From the research, $40 \%$ disagreed it was an effective tool in ecological restoration because of its monitoring and reward of credits to people involved in it. About $34 \%$ of the community members mostly farmers believed it was a good approach in ecological restoration provided their efforts in restoration could be monitored and rewarded. 


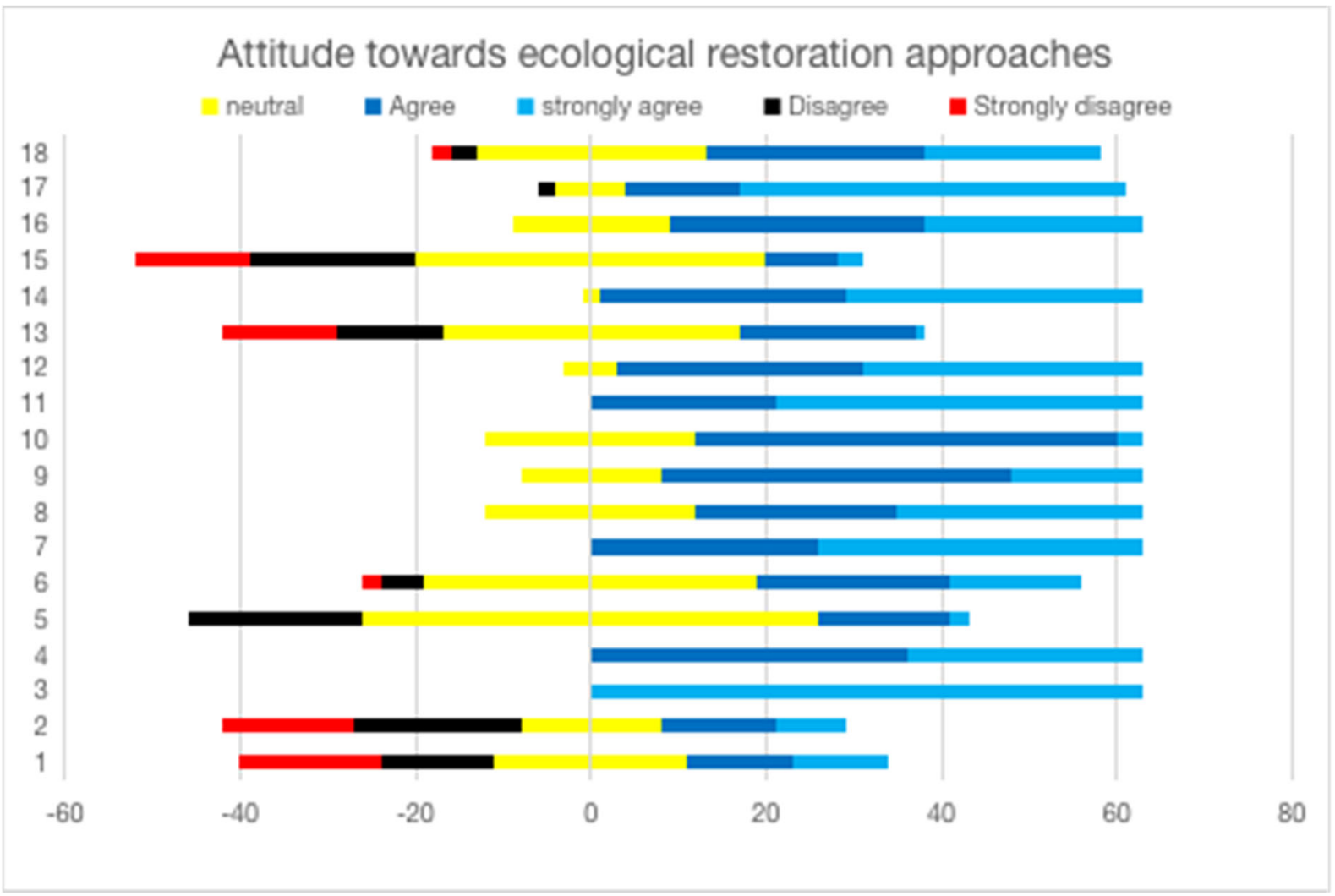

FIGURE 2 ATTITUDE TOWARDS ECOLOGICAL RESTORATION APPROACHES

\section{CONCLUSIONS}

Community mining is an effective program of involving community members in mining projects. Big mining companies in Ghana are believed to practice community mining to some extent but its effectiveness needs to be improved. Community leaders and investors need to play important roles in making mining activities friendlier to community members through employment and participation in decision making. According to Ghana web article (Article no.1058602) published on September 13, 2020, Government's Community mining Programme (CMP), an initiative in the making since 2018, has the potential to curb the environmentally destructive, and immensely dangerous practice of illegal small-scale mining.

\section{REFERENCES}

Adams, W. M., Perrow, M. R. and Carpenter, A. (2005). Perceptions of river managers of institutional constraints on floodplain restoration in the UK. Journal of environmental planning and management 48(6):877-889.

Apfelbaum, S.I., and A. Haney. (1989). Management of degraded oak savanna remnants in the upper Midwest: Preliminary results from three years of study. Pages 290-291 in proceedings of the society for ecological restoration and management, Oakland, California, USA.

Apfelbaum, S.I., and C. Sams. (1987). Ecology and control of reed canary grass (phalarisarundinacea l.). Natural areas Journal 7(2):69-74.

Ariel A., Andrea G., and Tamar D. (2017). Inter basin water transfer for the rehabilitation of a transboundary Mediterranean stream. Journal of environmental management, 202, (276), (2017). Australian minerals and energy industries. UNSW press \& Ameef, Sydney, 227-264.

Bash, J. S., and Ryan C.M. (2002). Stream restoration and enhancement projects: is anyone monitoring? Environmental management 29(6):877-885.

Bernhardt, E. S., Sudduth E. B., Palmer M. A., (2007). Restoring rivers one reach at a time: results from a survey of U.S. River restoration practitioners. Restoration ecology 15(3):482-493.

Breckenridge, L. P. (2006). Special challenges of transboundary coordination in restoring freshwater ecosystems. Pacific McGeorge global business \& development law journal 19(1):13-32.

Buijs, A. E. (2009). Public support for river restoration. A mixed-method study into residents' support for and framing of river management and ecological restoration in the Dutch floodplains. Journal of environmental management 90(8):2680-2689.

Callicot, J. B., and Nelson M., (1989). The great new wilderness debate. Georgia university press, Athens, Georgia, 
USA.

Clewell, A. F., and Aronsson J. 2007. Ecological restoration: principles, values, and structure of an emerging profession. Island press, Washington, D.C., USA.

Baker, S.R., Gardener, J.H., and Ward, S.C. (1995), Bauxite mining environment management and rehabilitation practices in Western Australia. In Proceedings of the Australian Institute of Mining and Metallurgy, World's Best Practice in Mining and Mineral Processing Conference. Sydney, Australia, 17-18 May 1995.

Bell, L.C. (1996). Rehabilitation of disturbed land in environmental management.

Bradshaw, A.D. (1984), Land restoration: Now and in the future. SER. B, 223: 1-23.

Bradshaw, A.D. (1999), The importance of nitrogen in the remediation of degraded land.

Bradshaw, A.D. (1990), The reclamation of derelict land and the ecology of ecosystems.

Brundrett, M., Abbott, L., Jasper, D., Ashwath, N., Malajczuk, N. \& Bougher, N.(1992b), Mycorrhizal associations of plants in disturbed and undisturbed soils of the alligator rivers region: part ii, preliminary report progress report, September 1992

Bullock J, Aronson J, Newton A, Pywell R, Rey-benayas J. (2011). Restoration of ecosystem services and biodiversity: Conflicts and opportunities. Trends in ecology \& evolution 26:541-549.

Bunso Cocoa College (1987). A guide to cocoa cultivation, a handbook for practical work, 35p.

Callicot, J. B., and Nelson, M. editors. (1989). The great new wilderness debate. Georgia university press, Athens, Georgia, USA.

Clewell, A. F., and Aronsson, J. (2007). Ecological restoration: principles, values, and structure of an emerging profession. Island press, Washington, D.C., USA.

Cairns, Jr., J. (1993), Ecological restoration: Maintaining per capita ecosystem services while the human population grows to ten billion.

Central intelligence agency (2006). World fact book: Uganda, people. Accessed 26 April 2006.

Coenen, F. H. J. M., Huitema, D. and O’toole L. J. (1998). Participation and environment. Page 126.

Drenthen, M. (2009). Ecological restoration and place attachment: Emplacing non-places?

Environmental values 18:285-312.

Eden, S., and Tunstall, T. (2006). Ecological versus social restoration? How urban river restoration challenges but also fails to challenge the science-policy nexus in the United Kingdom. Environment and planning c: government and policy 24:661-680.

Ekker, T. (2004). The idea of wilderness. International Journal of wilderness 10(1):15-17.

Elliot, R. (1982). Faking nature. Inquiry 25(1):81-93.

Ecosystem marketplace. (2012). State of the forest carbon markets 2012: Leveraging the landscape.

Ecosystems and human well-being: biodiversity synthesis," (report, millennium ecosystem assessment, (2005).

Fischer, f. (1998). Beyond empiricism: Policy inquiry in post positivist perspective. Policy studies 26(1):129-146.

Fu, Bo-Jie \& Zhuang, Xu-liang \& Jiang, Guibin \& Shi, Jianbo \& Lu, and. (2007). FEATURE: Environmental Problems and Challenges in China. Environmental Science \& Technology - ENVIRON SCI TECHNOL. 41. $10.1021 / \mathrm{es} 0726431$.

Guan, Lixin \& Sun, Ge \& Cao, Shixiong. (2011). China's Bureaucracy Hinders Environmental Recovery. Ambio. 40. 96-9. 10.1007/s13280-010-0112-6.

Liu, Jianguo. (2010). China's Road to Sustainability. Science. 328. 50-50. 10.1126/science.1186234.

Que, S., Wang, L., Awuah-Offei, K. and Chen, Y. (2018). "The Status of the Local Community in Mining Sustainable Development beyond the Triple Bottom Line.” Sustainability 10(6): 1-11.

Wan, J., Zhang, H.Y. and Wang, J.N., (2005). Policy evaluation and framework discussion of ecological compensation mechanism in China. Research of Environmental Sciences. 18. 1-8. 